\title{
Supercapacitance of Single-Walled Carbon Nanotubes-Polypyrrole Composites
}

\author{
Matei Raicopol, ${ }^{1}$ Alina Pruna, ${ }^{2}$ and Luisa Pilan ${ }^{1}$ \\ ${ }^{1}$ Faculty of Applied Chemistry and Materials Science, University Politehnica of Bucharest, 132 Calea Griviţei, \\ 010737 Bucharest, Romania \\ ${ }^{2}$ Faculty of Physics, University of Bucharest, 405 Atomistilor, 769231 Magurele, Romania
}

Correspondence should be addressed to Luisa Pilan; luisa_pilan@yahoo.com

Received 31 May 2013; Accepted 17 July 2013

Academic Editor: Filiz Kuralay

Copyright (C) 2013 Matei Raicopol et al. This is an open access article distributed under the Creative Commons Attribution License, which permits unrestricted use, distribution, and reproduction in any medium, provided the original work is properly cited.

\begin{abstract}
The composites based on carbon nanotubes (CNTs) and conducting polymers (CPs) are promising materials for supercapacitor devices due to their unique nanostructure that combines the large pseudocapacitance of the CPs with the fast charging/discharging double-layer capacitance and excellent mechanical properties of the CNTs. Here, we report a new electrochemical method to obtain polypyrrole (PPY)/single-walled carbon nanotube (SWCNT) composites. In the first step, the SWCNTs are covalently functionalized with monomeric units of pyrrole by esterification of acyl chloride functionalized SWCNTs and N-(6-hydroxyhexyl)pyrrole. In the second step, the PPY/SWCNTs composites are obtained by copolymerizing the pyrrole monomer with the pyrrole units grafted on SWCNTs surface using controlled potential electrolysis. The composites were further characterized by cyclic voltammetry and electrochemical impedance spectroscopy. The results showed good electrochemical charge storage properties for the synthesized composites based on PPY and SWCNTs covalently functionalized with pyrrole units making them promising electrode materials for high power supercapacitors.
\end{abstract}

\section{Introduction}

Currently, electrochemical capacitors are attracting much attention for use in high power energy-storage devices $[1,2]$. Many attempts have been devoted to the use of electronically conducting polymers as electrode materials in electrochemical capacitors, often called supercapacitors [3].

Especially polyaniline (PANI) and polypyrrole (PPY) have been considered as the most promising materials for this application due to their excellent capacity for energy storage, easy synthesis, higher conductivity, and lower cost than many other conducting polymers [4].

However, conducting polymer films suffer from mechanical and chemical instability in life cycle tests and low conductivity in the reduced or neutral states. These are directly related to the life cycle of conducting polymer-based supercapacitors [4].

Due to their unique nanostructure that combines the redox charge storage mechanism of conducting polymers with the high surface area and nanoporosity of carbon nanotube (CNT) films, recent research has sought to combine carbon nanotubes and conductive polymers for use as composite electrodes in supercapacitors [5-11].

These composites structures were commonly prepared by electrogeneration of a polymer on electrodes already modified by adsorbed CNTs coatings [12] or by electropolymerization of a monomer in the presence of negatively charged CNTs acting as polymer dopants [13]. Only few attempts were devoted to the electrochemical copolymerization of CNTs previously functionalized by aniline groups [14] or pyrrole groups [15].

This work focuses on a new fabrication route to prepare PPY/CNTs composite electrodes for use as electrochemical capacitors, that is, the monomer copolymerization with the pyrrole units grafted on single-walled carbon nanotubes (SWCNTs) surface by galvanostatic electropolymerization. Pyrrole functionalized CNTs have been synthesized by chemical binding of carboxylic functionalized CNTs, commercially available, and N-(6-hydroxyhexyl)pyrrole. The hydroxyhexyl chain served as a flexible spacer to facilitate the chemical 


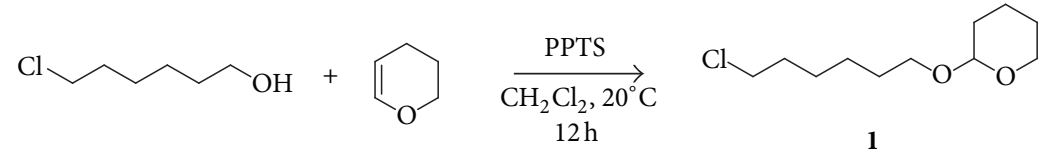

(a) 1-chloro-6-(tetrahydropyranyl-2-oxy)-hexane (1) synthesis

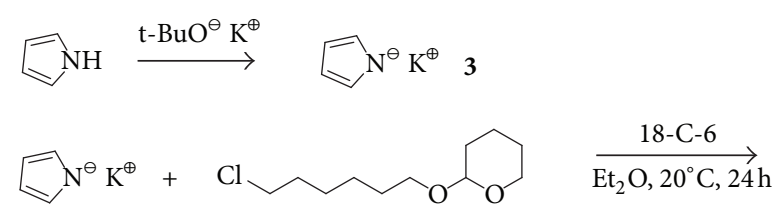

(b) N-[6-(tetrahydropyranyl-2-oxy)hexyl] pyrrole (2) synthesis
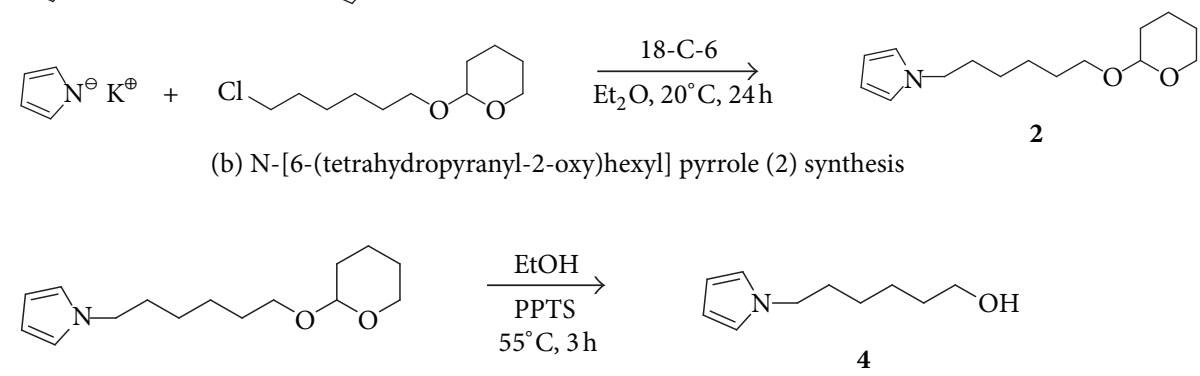

(c) N-(6-hydroxyhexyl)pyrrole (3) synthesis

SCHEME 1

1-chloro-6-(tetrahydropyranyl-2-oxy)-hexane

${ }^{1} \mathrm{H}-\mathrm{RMN}\left(400 \mathrm{MHz}, \delta, \mathrm{CDCl}_{3}\right): 4.56, \mathrm{~s}, 1 \mathrm{H}$

$\left(\mathrm{H}^{16}\right)$; 3.86, t, $1 \mathrm{H}\left(\mathrm{H}^{6}\right) ; 3.73$, q,

$1 \mathrm{H}\left(\mathrm{H}^{14}\right) ; 3.39, \mathrm{q}, 1 \mathrm{H}\left(\mathrm{H}^{15}\right)$;

3.53, $\mathrm{m}, 3 \mathrm{H}\left(\mathrm{H}^{7}, \mathrm{H}^{1}\right) ; 1.38-1.82$,

$\mathrm{m}, 14 \mathrm{H}\left(\mathrm{H}^{8}-\mathrm{H}^{13}, \mathrm{H}^{2}-\mathrm{H}^{5}\right)$;

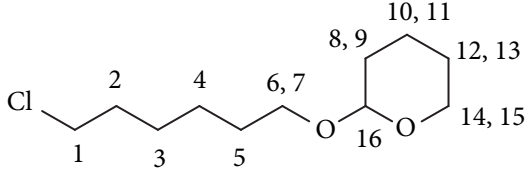

N-[6-(tetrahydropyranyl-2-oxy)hexyl] pyrrole

${ }^{1} \mathrm{H}-\mathrm{RMN}\left(400 \mathrm{MHz}, \delta, \mathrm{CDCl}_{3}\right): 6.61 ; \mathrm{t} ; 2 \mathrm{H}$,

$J=2.4 \mathrm{~Hz}\left(\mathrm{H}^{17}\right) ; 6.11, \mathrm{t}, 2 \mathrm{H}$,

$J=2.4 \mathrm{~Hz}\left(\mathrm{H}^{18}\right) ; 4.56, \mathrm{~m}, 1 \mathrm{H}\left(\mathrm{H}^{16}\right) ; 3.81, \mathrm{t}, 1 \mathrm{H}$,

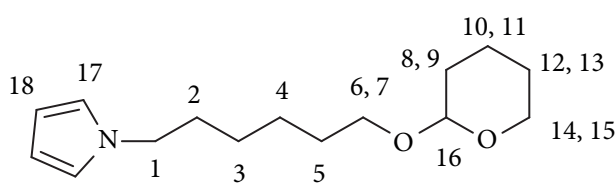

$J=7.2 \mathrm{~Hz}\left(\mathrm{H}^{6}\right) ; 3.72, \mathrm{cv}, 1 \mathrm{H}\left(\mathrm{H}^{14}\right) ; 3.48, \mathrm{t}, 3 \mathrm{H}$

$\left(\mathrm{H}^{7}, \mathrm{H}^{1}\right) ; 3.37, \mathrm{cv}, 1 \mathrm{H},\left(\mathrm{H}^{15}\right) ; 1.23-1.76, \mathrm{~m}, 14 \mathrm{H}\left(\mathrm{H}^{8}-\mathrm{H}^{13}, \mathrm{H}^{2}-\mathrm{H}^{5}\right)$

$\mathrm{N}$-(6-hydroxyhexyl)pyrrole

${ }^{1} \mathrm{H}-\mathrm{RMN}\left(400 \mathrm{MHz}, \delta, \mathrm{CDCl}_{3}\right): 6.62, \mathrm{t}, 2 \mathrm{H}$,

$J=2.4 \mathrm{~Hz}\left(\mathrm{H}^{7}\right) ; 6.1, \mathrm{t}, 2 \mathrm{H}, J=2.4 \mathrm{~Hz}\left(\mathrm{H}^{8}\right)$;

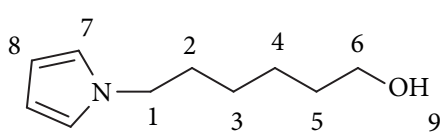

$3.84, \mathrm{t}, 2 \mathrm{H}, J=6.8 \mathrm{~Hz}\left(\mathrm{H}^{6}\right) ; 3.52, \mathrm{t}, 2 \mathrm{H}$,

$J=6.8 \mathrm{~Hz}\left(\mathrm{H}^{1}\right) ; 2.97, \mathrm{~s}, 1 \mathrm{H}\left(\mathrm{H}^{9}\right) ; 1.75, \mathrm{cv}, 4 \mathrm{H}\left(\mathrm{H}^{2}, \mathrm{H}^{5}\right) ; 1.35-1.53, \mathrm{~m}, 4 \mathrm{H}\left(\mathrm{H}^{3}, \mathrm{H}^{4}\right)$

SCHEMe 2

coupling between pyrrole radical cations in the polymerization process. This method affords the obtaining of composite materials with good electrochemical charge storage properties and, in the same time, leads to a simple and reproducible formation of organic film with precise spatial resolution over surfaces, whatever their size and geometry.

The morphology and electrochemical properties of the PPY/CNTs composites were characterized in order to evaluate their possible application for pseudocapacitors.

\section{Materials and Methods}

2.1. Reagents and Apparatus. Carboxylic acid functionalized single-walled carbon nanotubes $(4-5 \mathrm{~nm} \times 0.5-1.5 \mu \mathrm{m})$ were purchased from Aldrich. Pyrrole (98\%, Aldrich) was used as received. All other chemicals were analytical grade. The electrochemical measurements including cyclic voltammetry (CV) and electrochemical impedance spectroscopy (EIS) were performed in $0.1 \mathrm{M} \mathrm{LiClO}_{4}$ solution in propylene 


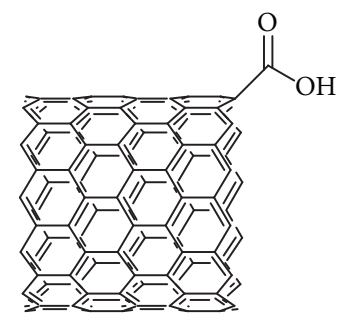

5

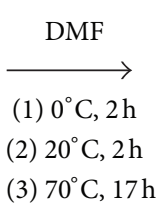

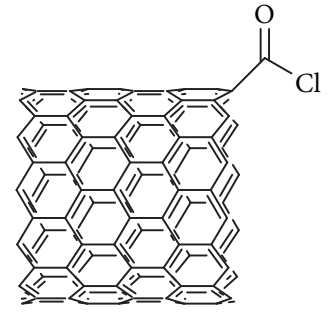

6

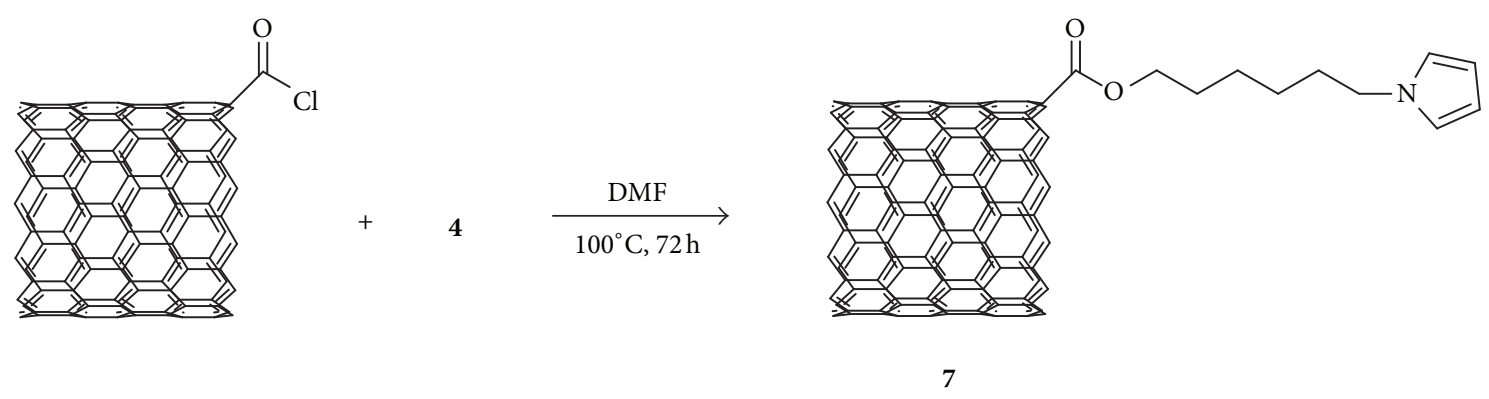

SCHEME 3

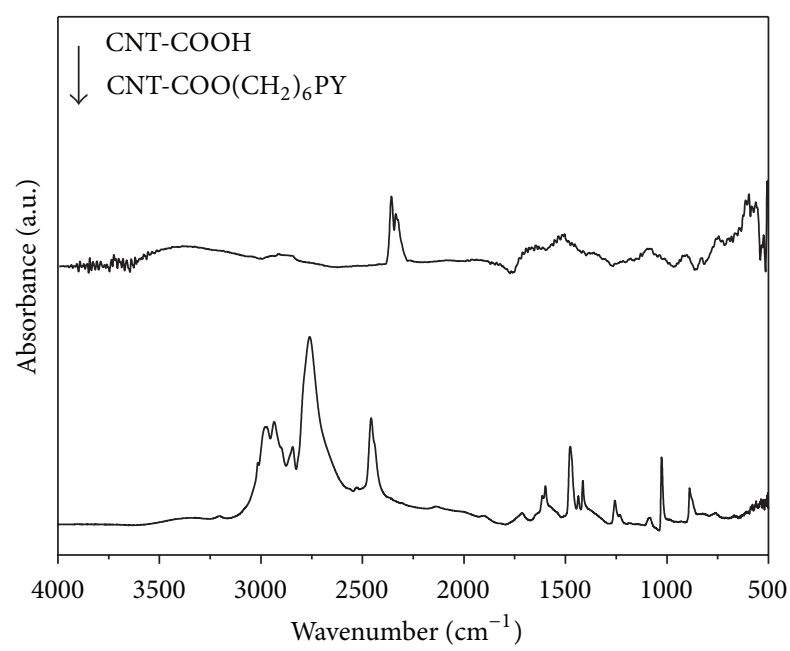

FIGURE 1: FTIR spectra of CNTs-COOH and pyrrole functionalized CNTs.

carbonate with a $128 \mathrm{~N}$ Autolab potentiostat. A threeelectrode configuration consisting of Pt (Metrohm, disks, diameter $2 \mathrm{~mm})$ as working electrodes, $\mathrm{Ag} / \mathrm{AgCl}\left(\mathrm{LiCl}_{\text {sat }}\right.$ in ethanol) as reference electrode, and a $\mathrm{Pt}$ wire as counter electrode was used. 1H-NMR measurements were carried out using a Bruker Avance II $500 \mathrm{MHz}$ spectrometer. IR absorption spectra were recorded with a Nicolet 60 SX FTIR spectrometer. Scanning electron microscopic (SEM) analysis was done using a JEOL JSM-5400 microscope working at $30 \mathrm{kV}$.

2.2. Chemical Synthesis of CNTs Functionalized with Pyrrole Units. Pyrrole functionalized CNTs have been synthesized by chemical binding of carboxylic functionalized CNTs, commercially available, and N-(6-hydroxyhexyl)pyrrole via ester formation.

$\mathrm{N}$-(6-hydroxyhexyl)pyrrole synthesis is presented in Scheme 1. Since alkylation of pyrrole cannot be done directly by treating the potassium salt of pyrrole with 6-chloro-1hexanol, with the $\mathrm{OH}$ group being a stronger acid than the pyrrole $\mathrm{NH}$, dihydropyran was used to protect the $\mathrm{OH}$ group. Thus, 1-chloro-6-(tetrahydropyranyl-2-oxy) hexane $\mathbf{1}$ was obtained from the reaction of 6-chloro-1-hexanol with 3,4 -dihydro- $2 \mathrm{H}$-pyran in the presence of pyridinium $p$ toluenesulfonate (PPTS) as catalyst. Alkylation of the potassium salt of pyrrole 3 obtained from pyrrole and potassium tert-butoxide with the compound $\mathbf{1}$ was performed under phase transfer catalysis in the presence of 18-crown- 6 ether. $\mathrm{N}$-(6-hydroxyhexyl)pyrrole 4 was obtained by deprotection of the hydroxyl group by the treatment of compound 2 with PPTS in methanol and it was purified by column chromatography (silica gel, gradient of petroleum ether: ethyl acetate).

Both compound $\mathbf{4}$ and the intermediates $\mathbf{1}$ and $\mathbf{2}$ have been structurally characterized by recording the spectra of ${ }^{1}$ H-NMR (Scheme 2).

The chemical binding of carboxylic functionalized SWCNTs and N-(6-hydroxyhexyl)pyrrole is presented in Scheme 3. It can be seen that, in the first step, carboxyl functionalized SWCNTs (CNT-COOH, 5) were chemically treated with oxalyl chloride to convert the carboxyl groups into acid chloride groups (CNT-COCl, 6), more reactive in the esterification reaction. Then, in the second step, the esterification of CNT-COCl with N-(6-hydroxyhexyl)pyrrole (4) was performed.

2.3. Electrochemical Synthesis of the Composite Films. The composite films were synthesized electrochemically via 


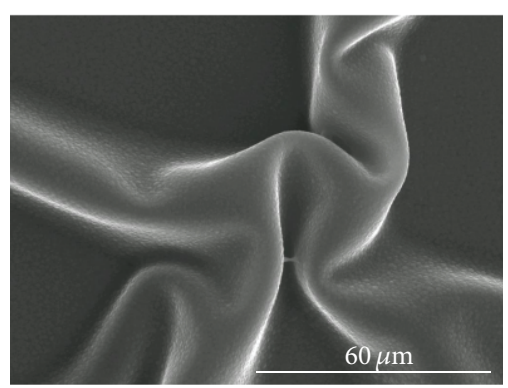

(a)

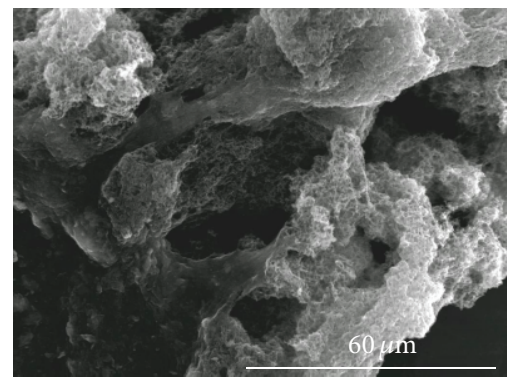

(d)

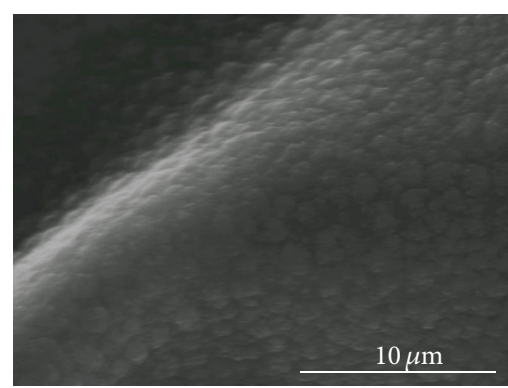

(b)

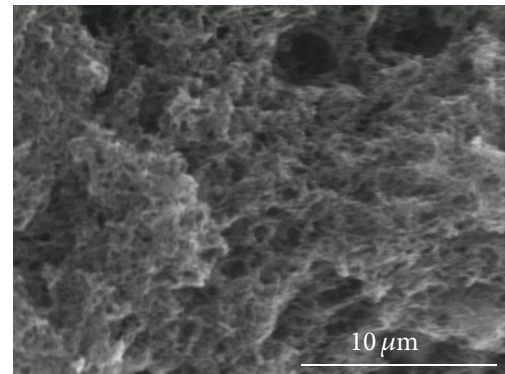

(e)

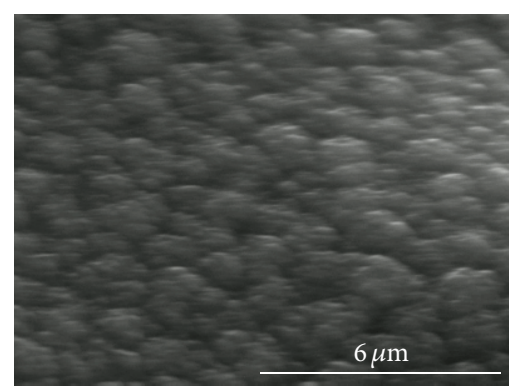

(c)

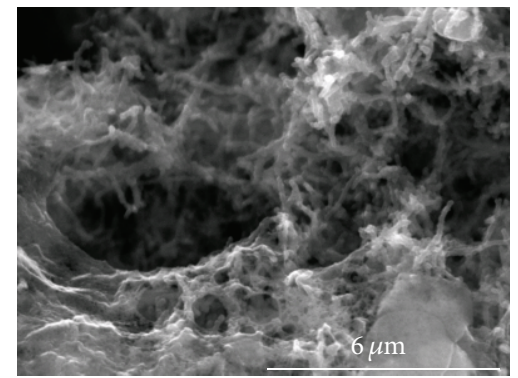

(f)

FIGURE 2: SEM morphology for PPY ((a)-(c)) and PPY/CNTs composite films ((d)-(f)) obtained galvanostatically at $0.1 \mathrm{~mA} \mathrm{~cm}^{-2}$ for $20 \mathrm{~min}$.

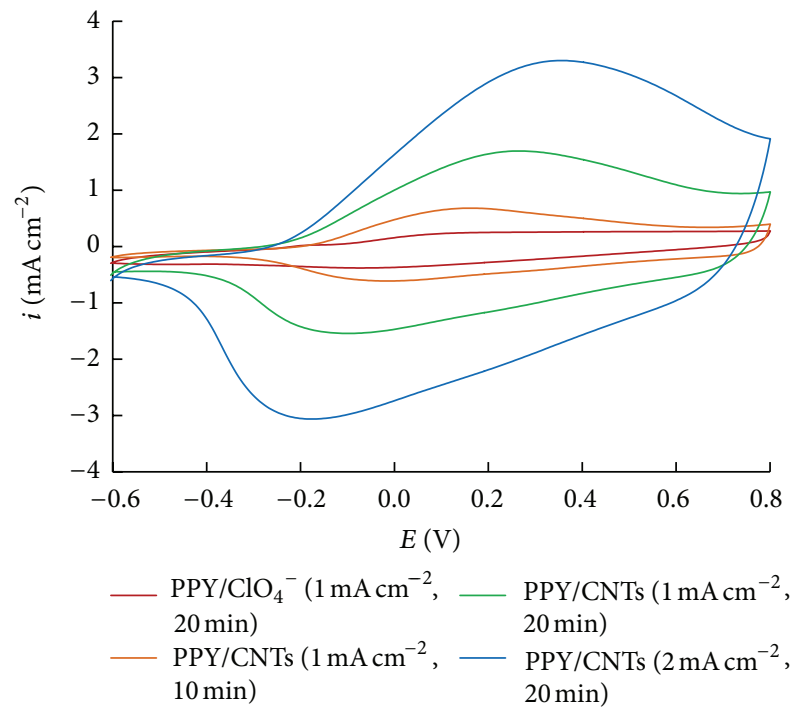

FIgURE 3: CVs in $0.1 \mathrm{M} \mathrm{LiClO}_{4}$ in propylene carbonate of the $\mathrm{PPY} / \mathrm{CNTs}$ composite films compared with the pure polymeric ones galvanostatically obtained at different charge densities.

codeposition from a solution containing both the functionalized CNTs and the pyrrole monomer. The pyrrole functionalized CNTs showed a good solubility in propylene carbonate; so the electropolymerization has been performed (galvanostatic method, at different current densities) from a propylene carbonate solution containing the pyrrole functionalized CNTs $\left(0.4 \mathrm{mg} \mathrm{mL}^{-1}\right), 0.05 \mathrm{M}$ pyrrole, and $0.1 \mathrm{M}$ $\mathrm{LiClO}_{4}$ as supporting electrolyte.

\section{Results and Discussion}

3.1. FTIR Analysis. IR absorption spectra of CNTs in the spectral range $500-4000 \mathrm{~cm}^{-1}$ are shown in Figure 1. For the analysis of the absorption features, we recorded IR spectra of both $\mathrm{CNT}-\mathrm{COOH}$ and pyrrole functionalized CNT. The spectra for CNT-COOH show the characteristic CNT absorption peaks similarly to other reports [16, 17] at $1505-1560 \mathrm{~cm}^{-1}$ (aromatic ring), $1308 \mathrm{~cm}^{-1}$ (-C-O), and $1640 \mathrm{~cm}^{-1}(-\mathrm{C}=\mathrm{C}-)$. Moreover, the stretching vibration of the $\mathrm{C}=\mathrm{O}$ group is identified at 1116 and $1690 \mathrm{~cm}^{-1}$ together with a hydroxyl-stretching weak band at $3300-3500 \mathrm{~cm}^{-1}$ [16]. The band at $1690 \mathrm{~cm}^{-1}$ disappears and strong absorption peaks appear at 1714, 1614, and $1598 \mathrm{~cm}^{-1}$ (pyrrole ring-stretching mode) as a result of the esterification of CNT-COCl with $\mathrm{N}$-(6-hydroxyhexyl)pyrrole. Moreover, the IR spectra of the pyrrole functionalized CNT depicted in Figure 1 show also a left region from 2800 to $3000 \mathrm{~cm}^{-1}$ with strong absorptions attributed to $\mathrm{C}-\mathrm{H}$ stretching modes in the $\mathrm{N}-(6-$ hydroxyhexyl)pyrrole [18]. Pyrrole bands attributable to C$\mathrm{H}$ out-of-plane, $\mathrm{C}-\mathrm{H}$ in-plane deformation vibrations, and $\mathrm{C}-\mathrm{N}$ stretching vibration were identified at 890,1026 , and $1256 \mathrm{~cm}^{-1}[18]$.

3.2. SEM Characterization. SEM showed that the surface morphology of the studied films differs remarkably between the PPY/CNTs and PPY $/ \mathrm{ClO}_{4}{ }^{-}$films. SEM image of PPY/CNTs film reveals a very fibrous three-dimensional reticular structure with interlocking pores unlike the PPY typical cauliflower morphology (Figure 2). This porous morphology allows also excellent electrolyte access with less resistance by providing enough pathways for the movement 


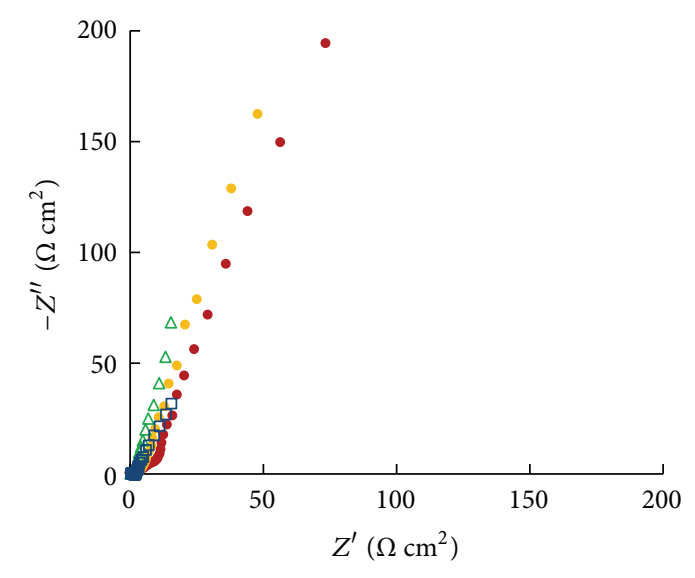

(a)

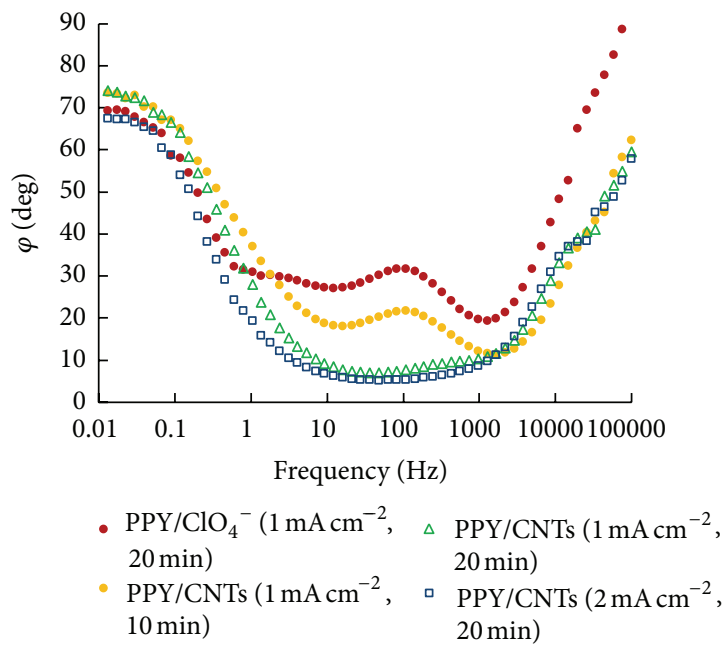

(c)

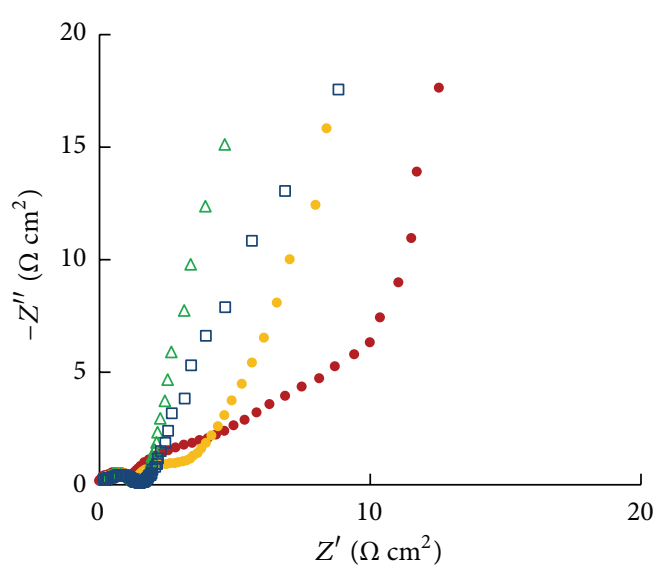

(b)

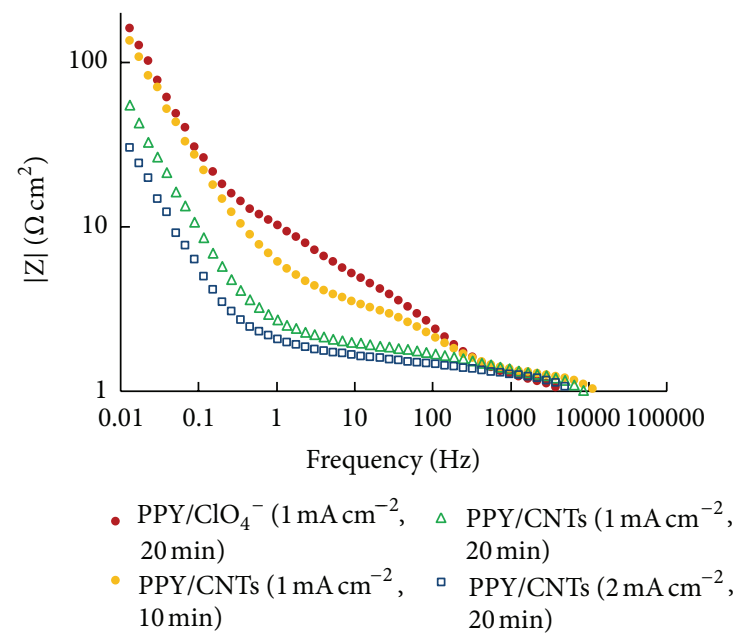

(d)

FIGURE 4: Nyquist ((a)-(b)) and Bode ((c)-(d)) diagrams for PPY/CNTs nanocomposite films compared to the pure polymeric one (obtained galvanostatically at different charge densities) at open circuit potentials in $0.1 \mathrm{M} \mathrm{LiClO}_{4}$ solution in propylene carbonate.

of ions and solvent molecules within the composite films that suggests improved electrochemical properties.

3.3. Cyclic Voltammetry Study. Figure 3 depicts the CVs of $\mathrm{PPY} / \mathrm{ClO}_{4}{ }^{-}$and PPY/CNTs films obtained at different charge densities in a wide potential range in order to explore all possible electrochemistries of the obtained films. The broad peaks observed in the voltammograms suggest a complicated redox process for the obtained modified electrodes. The comparison between the behaviour of the presented types of electrodes shows that the shape of the voltammograms is similar, but the composites exhibit higher currents than the pure polymeric ones, which can be translated into larger capacitance of the composites. The voltammetric behaviour agrees very well with the SEM observations of the porous morphology of the PPY/CNTs films.

3.4. EIS Analysis. A more detailed estimation of the electrochemical properties for the PPY $/ \mathrm{ClO}_{4}{ }^{-}$and PPY/CNTsbased supercapacitors can be carried out by EIS analysis.
The resulting Nyquist and Bode plots for $\mathrm{PPY} / \mathrm{ClO}_{4}{ }^{-}$and $\mathrm{PPY} / \mathrm{CNT}$ s systems are shown in Figure 4. The impedance plots for the PPY/CNTs systems obtained galvanostatically for $20 \mathrm{~min}$ at $1 \mathrm{~mA} \mathrm{~cm}^{-2}$ and $2 \mathrm{~mA} \mathrm{~cm}^{-2}$, respectively, show a good capacitor-like behavior with a small diffusion limitation (Figures 4(a) and 4(b)). The Bode diagram (Figures 4(c) and $4(\mathrm{~d})$ ) shows that the $\mathrm{PPY} / \mathrm{ClO}_{4}{ }^{-}$pure polymeric system and the composite PPY/CNTs films obtained at lower charge densities show a more complicated EIS behaviour, characterized by multiple time constants at intermediate frequencies. However, at low frequencies, these systems are also featured by a vertical trend in Nyquist diagram indicating capacitive behaviour according to the equivalent circuit theory.

The capacitances of the electrode materials were calculated, according to the equation $C=-1 /\left(2 \pi f Z_{\mathrm{im}}\right)(f=$ frequency; $Z_{\mathrm{im}}=$ imaginary impedance) from the slope of the linear correlation between the imaginary impedance and the reciprocal of the frequency at low frequencies (see Figure 5).

One can observe one order of magnitude higher capacitance values for PPY/CNTs film in respect of $\mathrm{PPY} / \mathrm{ClO}_{4}{ }^{-}$ pure polymeric films (Table 1). The higher capacitance of the 
TABLE 1: Capacitance and real impedance values at $0.01 \mathrm{~Hz}$ for pure polymeric and composite films.

\begin{tabular}{|c|c|c|c|c|}
\hline Modified electrode & $\begin{array}{c}\text { Slope of }-Z^{\prime \prime}= \\
f(1 / 2 \pi \cdot \text { frequency })\end{array}$ & $\begin{array}{c}Z_{r}\left(\Omega \mathrm{cm}^{2}\right) \text { at } \\
0.01 \mathrm{~Hz}\end{array}$ & $C\left(\mathrm{~F} \mathrm{~cm}^{-2}\right)$ & $\begin{array}{c}\text { Relative standard } \\
\text { deviation }(\%)\end{array}$ \\
\hline $\begin{array}{l}\mathrm{PPY} / \mathrm{ClO}_{4}^{-} \\
1 \mathrm{~mA} \mathrm{~cm}^{-2}, 20 \mathrm{~min}\end{array}$ & 12.646 & 73.5 & 0.079 & 4.23 \\
\hline $\begin{array}{l}\mathrm{PPY} / \mathrm{CNTs} \\
1 \mathrm{~mA} \mathrm{~cm}^{-2}, 10 \mathrm{~min}\end{array}$ & 10.807 & 47.8 & 0.093 & 4.57 \\
\hline $\begin{array}{l}\mathrm{PPY} / \mathrm{CNTs} \\
1 \mathrm{~mA} \mathrm{~cm}^{-2}, 20 \mathrm{~min}\end{array}$ & 4.4154 & 15.3 & 0.226 & 6.26 \\
\hline $\begin{array}{l}\mathrm{PPY} / \mathrm{CNTs} \\
2 \mathrm{~mA} \mathrm{~cm}^{-2}, 20 \mathrm{~min}\end{array}$ & 2.2193 & 10.2 & 0.451 & 6.73 \\
\hline
\end{tabular}

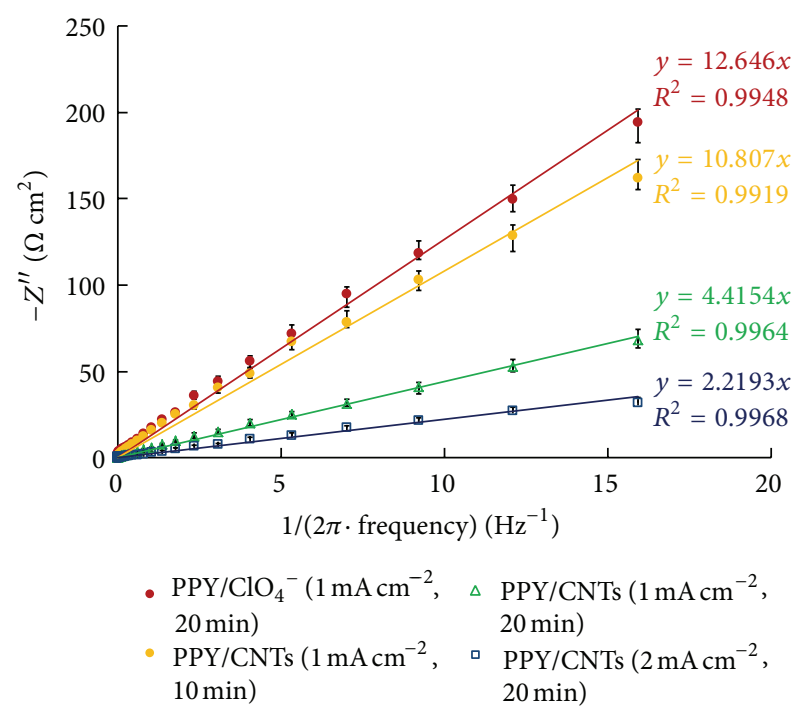

FIGURE 5: Capacitance evaluation for $\mathrm{PPY} / \mathrm{ClO}_{4}{ }^{-}$pure polymeric films and PPY/CNTs composites obtained at different charge densities.

composite films results obviously from the contribution of the embedded CNTs that provide interconnected pathways for electrons through the CNTs and ions through the pore network or the direct interaction between the delocalized electrons on polymer chains and the CNTs $[1,19]$.

The real impedance at low frequencies, where the capacitive behaviour dominates, is an indication of the combined resistance of the electrolyte and the film including both electronic and ionic contributions. The values of the real impedance at $0.01 \mathrm{~Hz}$ are also given in Table 1 . It can be seen that the PPY/CNTs films were significantly lower in resistance than $\mathrm{PPY} / \mathrm{ClO}_{4}{ }^{-}$films. It has been already mentioned that, in general, the real impedance of an electrode material also decreases as the material's porosity increases due to improved ionic accessibility $[1,20]$. This is in agreement with the SEM results that suggested much higher porosity in the composites than in the pure polymer counterparts.

The capacitance and real impedance values at $0.01 \mathrm{~Hz}$ presented in Table 1 demonstrate that the capacitive performance of PPY/CNTs composite electrodes can be simply controlled by varying electrodeposition charge, which is very useful for the performance regulating of power sources. The capacitance value is higher than the one reported in our previous study based on PPY/CNTs composite [1] and similar to the one reported by Wang et al. [13]. However, it is still low with respect to other conductive polymers/CNTs composite materials [20, 21]. Based on our knowledge, this is the first study concerning the composites based on PPY/CNTs composite electrodes obtained by pyrrole electrocopolymerization with pyrrole units grafted on CNTs surface; therefore, this research topic is in need of more investigations for further optimization of material properties.

Also, it is worth mentioning that this fabrication route provides composite coatings that are stable in organic and aqueous solvents. Our studies showed that, after an extensive washing procedure with solvents as acetonitrile or ethanol using sonication, the PPY/CNTs films could not be removed from the Pt electrode surface.

\section{Conclusions}

A new route is reported here for the fabrication of PPY/CNTs composite electrodes on the basis of pyrrole electrocopolymerization with pyrrole units grafted on CNTs surface. The covalent functionalization of CNTs with pyrrole units was carried out by the esterification of acyl chloride functionalized SWCNTs with N-(6-hydroxyhexyl)pyrrole. The electropolymerizable pyrrole group was chemically bound to the SWCNT backbone by using a hydroxyhexyl chain that served as a flexible spacer to facilitate the chemical coupling between pyrrole radical cations in the polymerization process. Future work will be dedicated to the optimisation of the polymerization process using appropriate spacers to assure an optimal accessibility of the pyrrole radical cations in the polymerization process.

PPY/CNTs composite films of various thicknesses can be grown by galvanostatic polymerisation onto platinum electrodes. SEM results confirmed the presence of welldistributed, networked nanotubes that are individually coated with PPY, thus forming a highly porous composite structure. Compared with similarly grown pure PPY films, the composite films exhibit better electrochemical responses. The capacitance per geometric electrode surface area $\left(\mathrm{F} \mathrm{cm}^{-2}\right)$ of the PPY/CNTs composite films 
increases relative to the electropolymerization charge, reaching $0.226 \mathrm{~F} \mathrm{~cm}^{-2}$, while the capacitance of similarly grown $\mathrm{PPY} / \mathrm{ClO}_{4}{ }^{-}$films was only $0.079 \mathrm{~F} \mathrm{~cm}^{-2}$.

\section{Acknowledgment}

This work was supported by CNCS-UEFISCDI, project PN II-RU, no. 15/05.08.2010, code TE_153.

\section{References}

[1] V. Branzoi, L. Pilan, and F. Branzoi, "Nanocomposite films obtained by electrochemical codeposition of conducting polymers and carbon nanotubes," Electroanalysis, vol. 21, pp. 557562, 2009.

[2] C. Peng, S. Zhang, D. Jewell, and G. Z. Chen, "Carbon nanotube and conducting polymer composites for supercapacitors," Progress in Natural Science, vol. 18, no. 7, pp. 777-788, 2008.

[3] B. E. . Conway, Electrochemical Supercapacitors, Kluwer Academic, Plenum Publishers, New York, NY, USA, 1999.

[4] V. Khomenko, E. Frackowiak, and F. Béguin, "Determination of the specific capacitance of conducting polymer/nanotubes composite electrodes using different cell configurations," Electrochimica Acta, vol. 50, no. 12, pp. 2499-2506, 2005.

[5] V. Branzoi, F. Branzoi, and L. Pilan, "Electrochemical fabrication and capacitance of composite films of carbon nanotubes and polyaniline," Surface and Interface Analysis, vol. 42, no. 6-7, pp. 1266-1270, 2010.

[6] L. Pilan, M. Raicopol, A. Pruna, and V. Branzoi, "Polyaniline/carbon nanotube composite films electrosynthesis through diazonium salts electroreduction and electrochemical polymerization," Surface and Interface Analysis, vol. 44, no. 8, pp. 11981202, 2012.

[7] E. Frackowiak, "Carbon materials for supercapacitor application," Physical Chemistry Chemical Physics, vol. 9, pp. 1774-1785, 2007.

[8] V. Mottaghitalab, B. Xi, G. M. Spinks, and G. G. Wallace, "Polyaniline fibres containing single walled carbon nanotubes: enhanced performance artificial muscles," Synthetic Metals, vol. 156, pp. 796-803, 2006.

[9] J.-Y. Kima, K. H. Kima, and K. B. Kima, "Fabrication and electrochemical properties of carbon nanotube/polypyrrole composite film electrodes with controlled pore size," Journal of Power Sources, vol. 176, pp. 396-402, 2008.

[10] Y. Zhou, B. He, W. Zhou et al., "Electrochemical capacitance of well-coated single-walled carbon nanotube with polyaniline composites," Electrochimica Acta, vol. 49, pp. 257-262, 2004.

[11] G. A. Snook, G. Z. Chen, D. J. Fray, M. Hughes, and M. Shaffer, "Studies of deposition of and charge storage in polypyrrolechloride and polypyrrole-carbon nanotube composites with an electrochemical quartz crystal microbalance," Journal of Electroanalytical Chemistry, vol. 568, no. 1-2, pp. 135-142, 2004.

[12] N. G. Sahoo, Y. C. Jung, H. H. So, and J. W. Cho, "Polypyrrole coated carbon nanotubes: synthesis, characterization, and enhanced electrical properties," Synthetic Metals, vol. 157, no. 89, pp. 374-379, 2007.

[13] J. Wang, Y. Xu, X. Chen, and X. Sun, "Capacitance properties of single wall carbon nanotube/polypyrrole composite films," Composites Science and Technology, vol. 67, pp. 2981-2985, 2007.
[14] G. M. D. Macimento, P. Cario, R. W. Novickis, M. L. A. Temperini, and M. S. Dresselhaus, "Synthesis and characterization of single-wall-carbon-nanotube-doped emeraldine salt and base polyaniline nanocomposites," Journal of Polymer Science A, vol. 43, pp. 815-822, 2005.

[15] S. Cosnier and M. Holzinger, "Design of carbon nanotubepolymer frameworks by electropolymerization of SWCNTpyrrole derivatives," Electrochimica Acta, vol. 53, no. 11, pp. 3948-3954, 2008.

[16] C.-S. Wu, "Characterizing composite of multiwalled carbon nanotubes and POE- $g$-AA prepared via melting method ," Journal of Applied Polymer Science, vol. 104, pp. 1328-1337, 2007.

[17] U. Sahoo, M. Das, and P. L. Nayak, "Synthesis and Characterization of Graft Copolymerized of Methacrylicacid (MAA) onto Chitosan on Single Walled Carbon Nanotube," International Journal of Research in Pharmaceutical and Biomedical Sciences, vol. 4, no. 2, p. 486, 2013.

[18] H.-C. Lu, W.-T. Whang, and B.-M. Cheng, "Effect of alkyl position of pyrrole on structures and properties of conjugated polysquaraines," Synthetic Metals, vol. 160, no. 9-10, pp. 10021007, 2010.

[19] M. Hughes, G. Z. Chen, M. S. P. Shaffer, D. J. Fray, and A. H. Windle, "Electrochemical capacitance of a nanoporous composite of carbon nanotubes and polypyrrole," Chemistry of Materials, vol. 14, no. 4, pp. 1610-1613, 2002.

[20] C. Peng, J. Jin, and G. Z. Chen, "A comparative study on electrochemical co-deposition and capacitance of composite films of conducting polymers and carbon nanotubes," Electrochimica Acta, vol. 53, pp. 525-537, 2007.

[21] M. Wu, G. A. Snook, V. Gupta, M. Shaffer, D. J. Fray, and G. Z. Chen, "Electrochemical fabrication and capacitance of composite films of carbon nanotubes and polyaniline," Journal of Materials Chemistry, vol. 15, no. 23, pp. 2297-2303, 2005. 

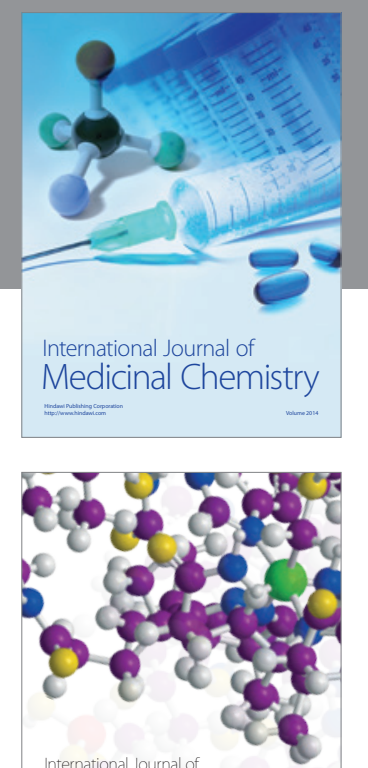

\section{Carbohydrate} Chemistry

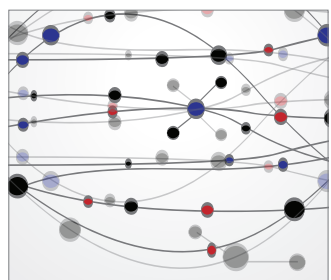

The Scientific World Journal
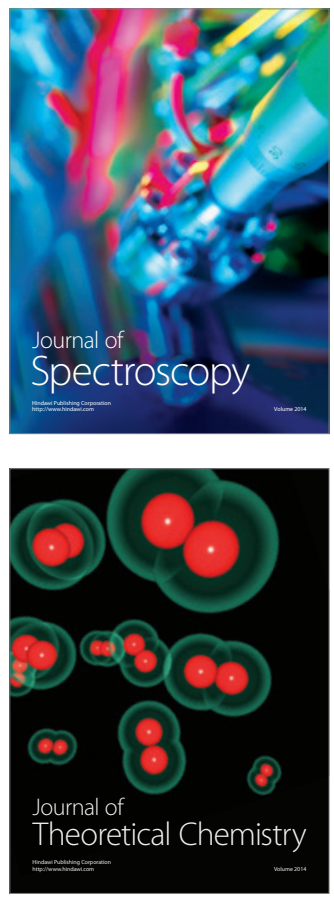
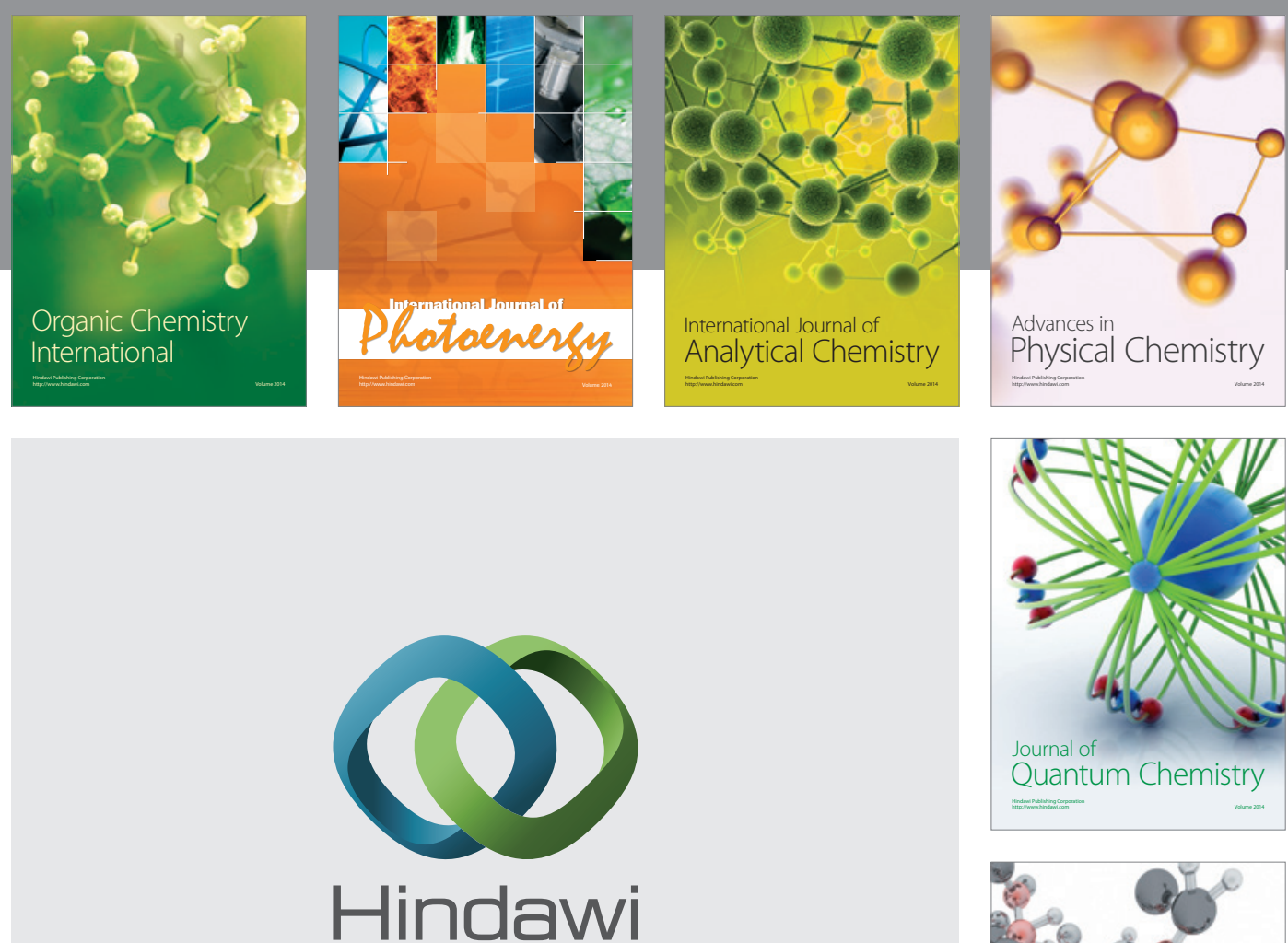

Submit your manuscripts at

http://www.hindawi.com

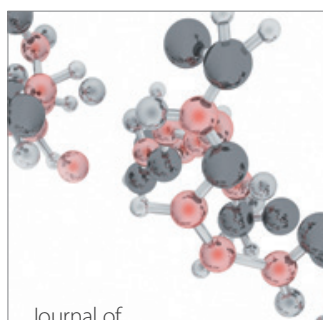

Analytical Methods

in Chemistry

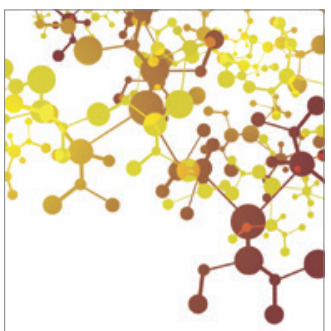

Journal of

Applied Chemistry

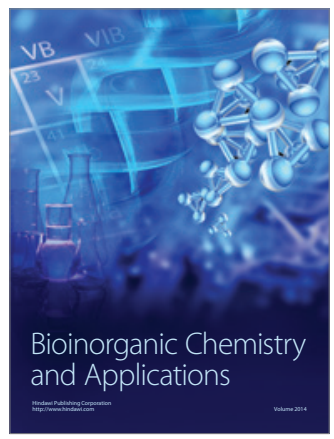

Inorganic Chemistry
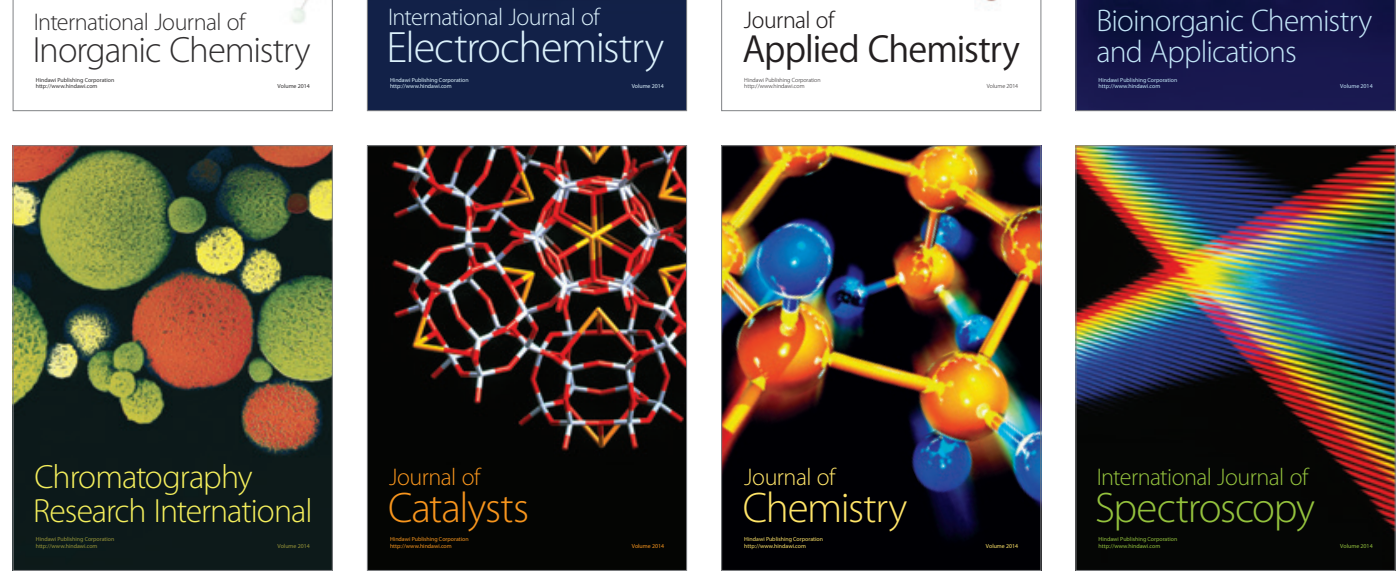